\title{
Applicability and calibration of an irregular cellular automata model for land use change
}

DOI:

10.1016/j.compenvurbsys.2017.05.005

\section{Document Version}

Accepted author manuscript

Link to publication record in Manchester Research Explorer

\section{Citation for published version (APA):}

Pinto, N., Antunes, A., \& Roca, J. (2017). Applicability and calibration of an irregular cellular automata model for land use change. Computers, Environment and Urban Systems, 65, 93-102.

https://doi.org/10.1016/j.compenvurbsys.2017.05.005

\section{Published in:}

Computers, Environment and Urban Systems

\section{Citing this paper}

Please note that where the full-text provided on Manchester Research Explorer is the Author Accepted Manuscript or Proof version this may differ from the final Published version. If citing, it is advised that you check and use the publisher's definitive version.

\section{General rights}

Copyright and moral rights for the publications made accessible in the Research Explorer are retained by the authors and/or other copyright owners and it is a condition of accessing publications that users recognise and abide by the legal requirements associated with these rights.

\section{Takedown policy}

If you believe that this document breaches copyright please refer to the University of Manchester's Takedown Procedures [http://man.ac.uk/04Y6Bo] or contact uml.scholarlycommunications@manchester.ac.uk providing relevant details, so we can investigate your claim.

\section{OPEN ACCESS}




\title{
APPLICABILITY AND CALIBRATION OF AN IRREGULAR CELLULAR
}

\section{AUTOMATA MODEL FOR LAND USE CHANGE}

\section{Nuno Pinto (corresponding author)}

Spatial Policy and Analysis Lab, Manchester Urban Institute, Department of Planning and Environmental Management, University of Manchester Oxford Rd, Manchester M13 9PL, United Kingdom

Telephone: +441612752729

E-mail: nuno.pinto@manchester.ac.uk

\section{António Pais Antunes}

CITTA, Department of Civil Engineering, University of Coimbra Rua Luis Reis Santos, 3030-788 Coimbra, Portugal

Telephone: +351239797139

E-mail: antunes@dec.uc.pt

\section{Josep Roca}

Centre for Land Policy and Valuation, BarcelonaTech Universitat Politecnica de Catalunya, Av Diagonal, 649, 4a planta, 08028 Barcelona, Spain

Telephone: +34934016396

E-mail: josep.roca@upc.edu

\begin{abstract}
Cellular automata (CA) models of spatial change have been developed and applied in the context of large regional or metropolitan areas and usually use regular cells, with spatial interactions and transition rules operating within fixed-size neighbourhoods. Model calibration has also been an area of intensive research with many models still using expertbased input to ensure visual calibration of modelled land use maps. In this paper, we present an innovative CA model where irregular cells and variable neighbourhoods are used to better represent space and spatial interaction. Calibration is based on an optimisation procedure that
\end{abstract}


uses particle swarm (PS) to determine the optimal set of parameters of the CA model. Hypothetical test instances are used to assess the CA model and its calibration to small urban areas. Our conclusion was that the use of PS ensures calibration results for the CA model that compare very well with results obtained through other approaches reported in the literature.

Keywords: cellular automata, irregular cells, land use change, particle swarm, calibration

\section{Introduction}

Models in general are abstract formulations of a reality they are designed to describe. These formulations may have different extents of adhesion to that reality, from a more theoretical and conceptual perspective to a fully-fledged degree of operationally. The extent to which models respond to this degree of abstraction must be accessed in terms of its applicability and in terms of the techniques and the outputs of their calibration.

This paper addresses the issues of applicability and calibration of cellular automata (CA) models to land use change and has three main goals. The first goal is to assess the applicability of a CA model to the research of urban change in small urban areas, which can be characterised by low levels of urbanisation and small sizes in population and in employment locations. CA are usually applied to the study of regional or metropolitan areas (Clarke et al., 1997, Silva and Clarke, 2002, White and Engelen, 1993, Lin et al., 2014, Basse et al., 2014, Guan and Clarke, 2010, Vliet et al., 2009, Barredo et al., 2003, Ward et al., 2000, White and Engelen, 1997), discarding the consideration of local problems within their regional contexts. Smaller urban areas tend to be less diverse in terms of land uses and have smaller number of possible changes due to be represented by less cells (when compared with larger urban areas with a same geographical representation in terms of cell form and size), thus posing challenges to a CA model. The second goal of this research regards the use of 
irregular cells on a CA approach. There is a relatively small and recent group of studies that developed CA models considering irregular cellular fabrics (Semboloni, 2000, Moreno et al., 2009b, O' Sullivan, 2001a, Stevens et al., 2007, Moreno et al., 2008, Abolhasani et al., 2016, Barreira-González et al., 2015, Chen et al., 2014, Moreno et al., 2009a, Stevens and Dragicevic, 2007, Wang and Marceau, 2013). This particular characteristic is of great importance when traditional regular cells, obtained from satellite images, do not represent well the spatial structure of the territory. Irregular cells based on the urban structure can be considered as natural spatial cells. The higher resolution at which census blocks are drawn considers the urban structure, holding at the same time structured and reliable information on demographics and built form, thus being a good irregular spatial partition. Finally, a third goal of the research is to evaluate the application of an optimisation-based calibration procedure using the particle swarm (PS) algorithm as a calibration engine for the CA model. PS is an algorithm proposed in the mid-1990s by Kennedy and Eberhart (1995) which is quite capable of dealing with complex problems in which multiple model parameters represent increasing interdependences between different phenomena.

We have previously used PS to calibrate a CA model applied to a real world case study where rapid urban growth was observed (Pinto and Antunes, 2010). We now focus on presenting and analysing the detailed formulation of PS as an optimization procedure for a CA model. The paper presents results of a set of calibration test instances that illustrate the capacity of the PS algorithm to deal with the high complexity of the CA model.

The paper is organized as follows: in section 2 a brief literature survey on CA and on the calibration of CA models is presented; section 3.1 is dedicated to presenting the CA model developed in our research; section 3.2 discusses the definition of performance measures, followed by the description of the calibration procedure in section 3.3; section 4 presents the set of hypothetical test instances used to assess model performance; in section 5 the 
calibration results are presented and discussed; finally, in section 6 some conclusions are drawn.

\section{A brief literature survey on cellular automata models and their calibration}

The concept of cellular automata was introduced in the late 1940s by John von Neumann and Stanislaw Ulam, who were facing (independently) the problem of devising sets of mathematical rules for simulating the self-reproduction and evolution of biological systems. The spatial nature of CA led Waldo Tobler to pioneer their introduction in urban studies (Tobler, 1979). This breakthrough was contemporary of a very turbulent period in spatial modelling, after Lee's criticisms on the development of large scale models (Lee, 1973). Because of this significant, although brief "dark age", CA was kept aside from the scientific spotlights until the mid-1980s, gaining a new breath with the advent of faster and more capable processing capabilities along with the development of more powerful database management tools. Tobler and also Helen Couclelis were responsible for giving CA the necessary scientific background for their application in geography and urban studies (Couclelis, 1985). They were followed by many other researchers in different parts of the world and many theoretical and operational models were developed. Couclelis $(1997,2005)$, Batty and Xie (1994), and Batty (2005) worked on theoretical issues regarding CA application to urban studies. White and Engelen (1993, 1997), Batty and Xie (1997), and Clarke et al. (1997) worked on the application of important evolutions of CA to real world problems. CA also benefited from the contemporary development of GIS concepts and their coupled use was approached, for example, by Wu (1998) and Batty et al. (1999). Since then, a series of papers were published using CA models as the core method to address urban growth (Barredo et al., 2003, Semboloni, 1997, Silva and Clarke, 2002, Ward et al., 2003). The use of irregular cells is quite scarce considering all the research made on CA: Semboloni (2000) used Voronoi polygons to model urban growth; O'Sullivan (2001a,b) combined CA 
and graph theory generating a set of neighbourhood scale irregular cells; Stevens et al. (2007) published work on high resolution irregular CA, in which the cell is a single land parcel. Moreno et al. (2008) and Moreno et al. (2009b) used a vector-based CA model where irregular cells evolve throughout time in size and form considering their transition values and variable neighbourhoods; Wang and Marceau (2013) developed a patch-CA model that aggregates neighbouring cells with similar land use to create a vector-based CA model; (Chen et al., 2014) also developed a patch-CA model that still operates with irregular cells to calculate transition potentials but then produces a vectorization of the cell space to increase representativeness; Abolhasani et al. (2016) and Barreira-González et al. (2015) used land parcels of homogeneous form.

Calibration always is an important research issue in the development of CA models. As important as the conceptual development of a model, calibration is aimed to ensure the necessary connection between simulation and reality. CA model calibration has been a subject of different approaches using different types of procedures, from sensitivity analysis to optimisation-based methods. SLEUTH (Clarke et al., 1997, Jafarnezhad et al., 2016, Onsted and Chowdhury, 2014, Rienow and Goetzke, 2015, Sakieh et al., 2015, Silva and Clarke, 2002) is calibrated through a two-step procedure: first, a visual calibration oriented for a broad parameter definition and debugging; second, a brute force calibration procedure where multiple runs are produced in order to generate enough model data to statistically compare reference data. Li and Yeh (2002) and Li et al. (2013), Almeida et al. (2008), Basse et al. (2014) and Altartouri et al. (2015) coupled CA models with artificial neural network formulations to calibrate transition rules and other components of the CA models. White et al. (1997), Barredo et al. (2003) and Li et al. (2014) used basic sensitivity analysis to calibrate the weighting parameters for the spatial interactions between land uses. 
Recent trends show that optimisation procedures are becoming more popular as tools to calibrate CA models. Feng and Liu (2012) used simulated annealing for calibrating the set of CA parameters of urban change in Chinese regions. (Kai) Cao et al. (2013) relied on multiobjective optimisation based on different formulations of a genetic algorithm approach to calibrate CA transition rules. Just recently, (Min) Cao et al. (2015) used the novel cuckoo algorithm to address the problem of transition rules. Feng et al. (2011) used PS to search for the overall set of optimal parameters of the CA model and Liao et al. (2014) relied on PS to calibrate the transition functions of the CA model based on a logistic regression considering a set of sample points in space.

The use of PS to calibrate CA models is rare in the literature. The authors have explored the application of PS coupled with an irregular cell CA model to a real world case study where the number of calibration parameters was very high (Pinto and Antunes, 2010). Feng et al. (2011) and Liao et al. (2014) have developed coupled CA models coupled with PS. These two approaches follow a structure similar to the one presented in our paper where PS is used to encapsulate the CA model to find its optimal set of calibration parameters considering different functions. This similarity of approaches is only a consequence of the very simple structure of the PS algorithm. Each particle represents a point of a space with multiple dimensions, which in turn represent parameters of the CA model. Main differences refer to the formulation of the CA models. Both Feng et al. (2011) and Liao et al. (2014) have a probabilistic approach to state transition and use regular cells in large scale regional problems whereas our model is based on the use of irregular cells and in the application of the CA model to small-scale problems. 


\section{Model presentation}

\subsection{The cellular automata model}

The CA model presented in this paper has a simple structure that derives from the classical formulation of $\mathrm{CA}$ with the consideration of constrained land use demand, following the concept introduced by White and Engelen (1993). We present here a brief overview of the structure and main components of the model, for a complete description of the model please see (Pinto and Antunes, 2010).

The model operates over an irregular cellular fabric obtained from census blocks to explicitly introduce in the model the capacity of dealing with existing data that is used in policy making and spatial planning and use this data to process the spatial dynamics of urban change.

Cell states are classified into a finite set of aggregated classes of land use; in this application the model makes use of a set of six aggregate states (or land use classes), which are intended to represent the whole set of urban land uses: urban low density (UL), urban high density (UH); industry (I), areas of expansion for urban (XU) and industrial (XI) uses (both represent non-occupied areas where, respectively, urban and industrial land uses are possible) and highly restricted uses that cannot be subject to use change (R).

Land use interaction takes place within a variable neighbourhood that is determined through model calibration using a circular neighbourhood with a radius $\delta$ (which is a calibration parameter). Its value influences, and is influenced by, all the other parameters at stake.

Transition rules incorporate planning regulations and simulate land use change based on a composite transition potential that takes into account cell accessibility, land use suitability, and neighbourhood interactions within the cell neighbourhood, which reflects the propensity/capacity of each cell to change state in each time step. This potential is a weighted value of those components according to the following expression: 


$$
P_{i, s}=\left(v_{P} \times S_{i, s}+\chi_{P} \times A_{i}+\theta_{P} \times N_{i, s}\right) \times \xi, \forall i \in \mathbf{C}, s \in \mathbf{S}
$$

where, for each cell $i$ from the set of cells $\mathbf{C}$, and for each state $s$ from the set of states $\mathbf{S}, P_{i, s}$ is the transition potential for state $s$ of cell $i ; S_{i, s}$ is the land use suitability value for state $s$ of cell $i$, assumed to be a binary variable that reflects the possibility or not to use that land for state $s ; A_{i}$ is the accessibility value of cell $i$, calculated considering travel times between cell centroids over the road network, which is classified in hierarchical levels (e.g., main roads, secondary roads, and local roads) according to road capacity and legal speed limits; $N_{i, s}$ is the neighbourhood effect for state $s$ of cell $i$ considering its neighbourhood $\mathbf{V}_{\mathbf{i}} ; v_{P}, \chi_{P}$ and $\theta_{P}$ are the calibration parameters for the three components of the transition potential; finally $\xi$ is a stochastic perturbation calculated using a random variable uniformly distributed in the interval ]0,1[, following the formulation by White and Engelen (1993). Cells are ranked using the value of their transition potential for each cell state (land use class) $s$ in each iteration $i$ and available land is consumed to meet land demand per land use class until the demand is satisfied.

$N_{i, s}$ is an aggregate value of the interactions $N_{i, s \mid j, r}$ between the states (or land uses) $s$ and $r$, located in two neighbouring cells $i$ and $j$. It is calculated through the following expression:

$$
N_{i, s}=\sum_{j \in \mathbf{V}_{i}} N_{i, s \mid j, r}, \forall i \in \mathbf{C}, \mathbf{V}_{\mathbf{i}}=\left\{j \in \mathbf{C}: d_{i j} \leq \delta\right\}, s, r \in \mathbf{S}
$$

where the neighbourhood effect $N_{i, s}$ is the sum of interactions $N_{i, s \mid j, r}$ between state $s$ in cell $i$ and all the states of neighbouring cells $j$ that belong to neighbourhood $\mathbf{V}_{\mathbf{i}}$ considering the neighbourhood distance parameter $\delta$ (which means that attraction or repulsion will only be taken into account if the cell $j$ is located within the neighbourhood $\mathbf{V}_{\mathbf{i}}$ ) and $d_{i, j}$ is the distance between cells $i$ and $j$.

For each pair of states, these interactions $N_{i, s \mid j, r}$ were considered to be a linear function of the distance between the cells, defined by the two calibration parameters, the interaction value in 
origin and the distance with null interaction, as depicted in Figure 1 which represents two examples of these relationships. The value of the function is 1 if the interaction between the states of two cells is characterized by maximum attraction, 0 if they do not interact (Figure 1(a)), and -1 if the interaction is characterized by maximum repulsion (Figure 1(b)). This value is obtained as follows:

$\left\{\begin{array}{l}N_{i, s \mid j, r}=\left(1-\frac{d_{i, j}}{d_{s, r}^{\max }}\right) \times N_{s, r}^{\max }, \forall i, j \in \mathbf{C}, s, r \in \mathbf{S} ; \Leftarrow d_{i j} \leq d_{s, r}^{\max } \\ 0 ; \text { otherwise }\end{array}\right.$

where $N_{s, r}^{\max }$ is the maximum value for the interaction between cells in state $s$ and in state $r$ (intercept of the line relating interaction with distance), and $d_{s, r}{ }^{m a x}$ is the distance for which the interaction is zero.

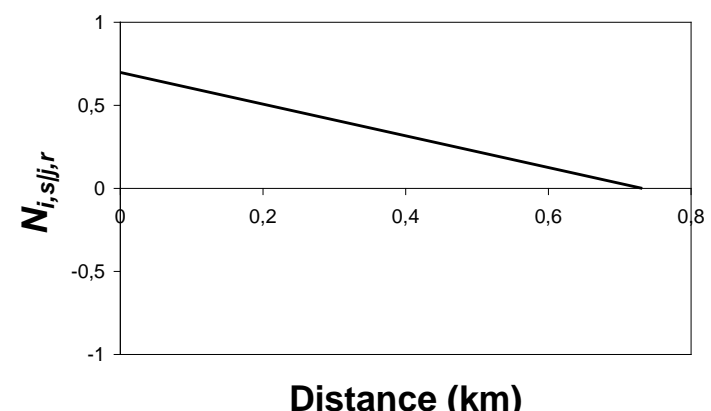

(a)

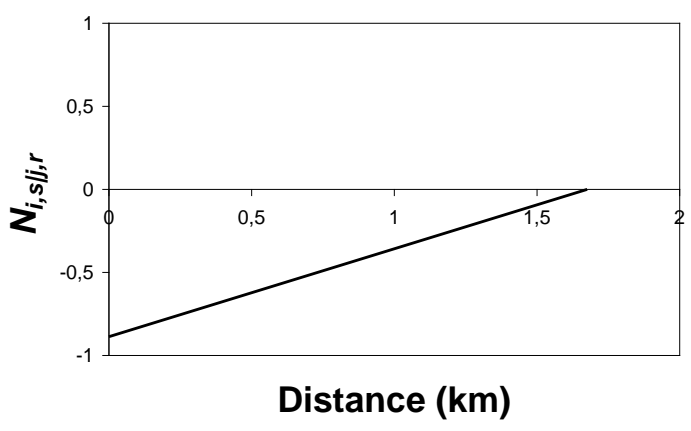

(b)

Figure 1 Two generic examples of neighbourhood effect relationships: (a) attraction, (b) repulsion

The transition potential of a cell is increased by a given value that depends on the distance between this cell and each neighbouring cell, if their states attract themselves (for example urban uses as UL and restrictive uses $\mathrm{R}$ exert attraction due to, for example, positive externalities of green amenities). In contrast, the potential is decreased by a given value if their states repel themselves (for example urban uses as UH and industrial uses I due to negative externalities like pollution). 
The time step, a fundamental component of dynamic models such as CA, can be defined by the user.

Thresholds of land use demand are determined through the evolution of population and employment densities considering the variation of household size and living standards over time.

\subsection{Measuring the cellular automata model performance}

Models must be adjusted to the reality they are supposed to address. For that it is necessary to implement in each model at least a measure of performance or fitness of adjustment. This fitness measure is a function of the set of calibration parameters and provides an indicator of how close to reality the simulation is. Each set of calibration parameters creates a unique value for the fitness function, which must be evaluated against the same value for reality. The assessment of the model performance was made using contingency matrices as well as simulation maps and the corresponding kappa index (Couto, 2003). There is a pertinent discussion about the value of using the kappa index for comparing class maps. Congalton and Green (2009) provided an ample support for its use due to the multiple applications of the measure, while Pontius and Millones (2011) provided evidence of the problems and lack of accuracy that the measure has when compared with other metrics derived from contingency matrixes. More recently, Grinblat et al. (2016) developed an in-depth evaluation of pros and cons of using kappa in different cell configurations. Our choice for using the kappa index comes mostly from the practicality of comparing results with other CA models in the literature with similar formulations (Barredo et al., 2003, Grinblat et al., 2016, Petrov et al., 2009). The use of different measures would make this comparison less reliable. The contingency matrix for two class maps is a matrix where each element, $m_{s r}$, expresses the number of cells classified in state $s$ in the simulation map which are in state $r$ in the reference map. Several comparison measures regarding the degree of agreement between two class 
maps can be extracted from a contingency matrix. The most used one is the kappa index, which value gets closer to one as the similarity between the two maps increases. In our model, a modified version of the kappa index was used to avoid the distortion that would have been produced if states that cannot take part in the urban dynamics - that is, state $\mathrm{R}$ (highly restricted uses) - were included in the computation. The consideration of cells in this state would be misleading by producing a large - though meaningless - agreement between simulation and reference maps, an improvement also proposed by van Vliet et al. (2011). The modified kappa index, $k M o d$, used as fitness function was calculated as follows:

$$
k_{\text {mod }}=\frac{n \sum_{i \in \mathbf{S}^{*}} m_{i i}-\sum_{i \in \mathbf{S}^{*}}\left(\sum_{j \in \mathbf{S}^{*}} m_{i j} \times \sum_{j \in \mathbf{S}^{*}} m_{j i}\right)}{n^{2}-\sum_{i \in \mathbf{S}^{*}}\left(\sum_{j \in \mathbf{S}^{*}} m_{i j} \times \sum_{j \in \mathbf{S}^{*}} m_{j i}\right)}, \mathbf{S}^{*}=\mathbf{S} /\{R\}
$$

where $n$ is the total number of elements in the contingency matrix and $m_{i j}$ is a generic element of the matrix.

\subsection{Calibration of the cellular automata model with particle swarm}

The calibration of a model can be achieved mainly through two different approaches (that sometimes may be combined): (1) performing a sensitivity analysis of each parameter's behaviour considering the other parameters fixed; or (2) running an optimisation procedure for searching the set of calibration parameters that optimize the fitness function chosen for the model. The first approach is based on a group of procedures that take place after the simulation. Visual comparison can be used to quickly assess the similarity between modelled and reference maps. After this initial procedure, a series of sensitivity analyses can be performed to evaluate how each parameter varies when the other parameters are controlled. This calibration approach becomes difficult to apply as the number of parameters increases. The main reason for using the second, optimisation based approach is to ensure an extensive 
search for the parameters, leading to the best possible values for the parameters given the fitness function of the CA model.

In our model the fitness function chosen to assess the quality of model results was the modified kappa index, kMod, described before. The value of this measure should be as close to 1 as possible. This characteristic of the fitness function also suggests the optimisation approach as a good method to calibrate the model.

The number of calibration parameters in our CA model is quite high: there are three accessibility parameters $\left(\alpha_{A}, \beta_{A}\right.$, and $\left.\gamma_{A}\right)$, four transition potential parameters $\left(\alpha_{P}, \chi_{P}, v_{P}\right.$ and $\left.\theta_{P}\right)$, the neighbourhood distance parameter and the 30 parameters of the neighbourhood effect relationships, totalling 38 calibration parameters.

For the problem at hand, the optimisation procedure chosen was the PS algorithm. This recent optimisation algorithm, credited to Kennedy (1997), has been giving promising results for complex optimisation problems. PS has its origins in the simulation of group and social behaviours, e.g. in the study of the synchronized movement of bird flocks and fish schools. The member's movement in those groups is the result of the individual effort to maintain an optimum distance between him and his neighbours in the group (Parsopoulos and Vrahatis, 2002). The movement of the swarm takes place in a multi-dimensional solution space. The individual's successes influence their searches and those of their peers (Kennedy, 1997). Interaction in these groups enhances progress towards a solution, as particles benefit from their own knowledge and from their neighbours' knowledge. In this technique the aim is not the survival of the fittest but the joint effort of the swarm in finding the best solution.

Each particle has a memory of its past search history, usually called the cognitive component. It represents the natural tendency of individuals to return to environments where they experienced their best performance. Formally, it is the distance that the particle is from its personal best position. Each particle also knows the search results of the swarm, called the 
social component. It represents the tendency of an individual to follow the success of other individuals. Formally, it is the distance that the particle is from its neighbours' best position (van den Bergh and Engelbrecht, 2006). PS does not guarantee convergence to a global optimum, therefore it is possible that they may end up in a local optimum (Bonyadi and Michalewicz, 2016). However, it has been shown empirically that they perform rather well in relation to other heuristic algorithms, e.g. genetic algorithms, with regard to both solution quality and, especially, computational time (one of the best-known comparisons is provided in Hassan et al. (2005)). Moreover, they do not require the parameter tuning effort of these other algorithms.

The formulation of PS is quite simple. It is based on a swarm of $p$ particles that will fly through the search space during $n$ iterations. The number of particles varies: it usually ranges from a few up to 60 particles (but there is no predetermined upper limit). The larger the swarm is, the better the search space tends to be searched. Each particle has $D$ dimensions: in this application of PS to the calibration of the CA model each calibration parameter is a PS dimension. The flowchart for the PS algorithm is depicted in Figure 2. Note that CA are embedded into the calibration process being called as many times as the number of PS iterations multiplied by the number of particles.

Two vectors of particle data are necessary: one vector to record the particle's position and another to record its velocity (velocity represents the position change in each iteration). Considering that the search space is $D$-dimensional, then the $i^{\text {th }}$ particle of the swarm can be represented by its positional, $D$-dimensional vector $\boldsymbol{X}_{\boldsymbol{i}}$

$$
X_{i}=\left(x_{i 1}, x_{i 2}, \ldots, x_{i D}\right)^{T}
$$

and by its velocity, $\boldsymbol{D}$-dimensional vector $\boldsymbol{X}_{\boldsymbol{g}}$

$V_{i}=\left(v_{i 1}, v_{i 2}, \ldots, v_{i D}\right)^{T}$. 


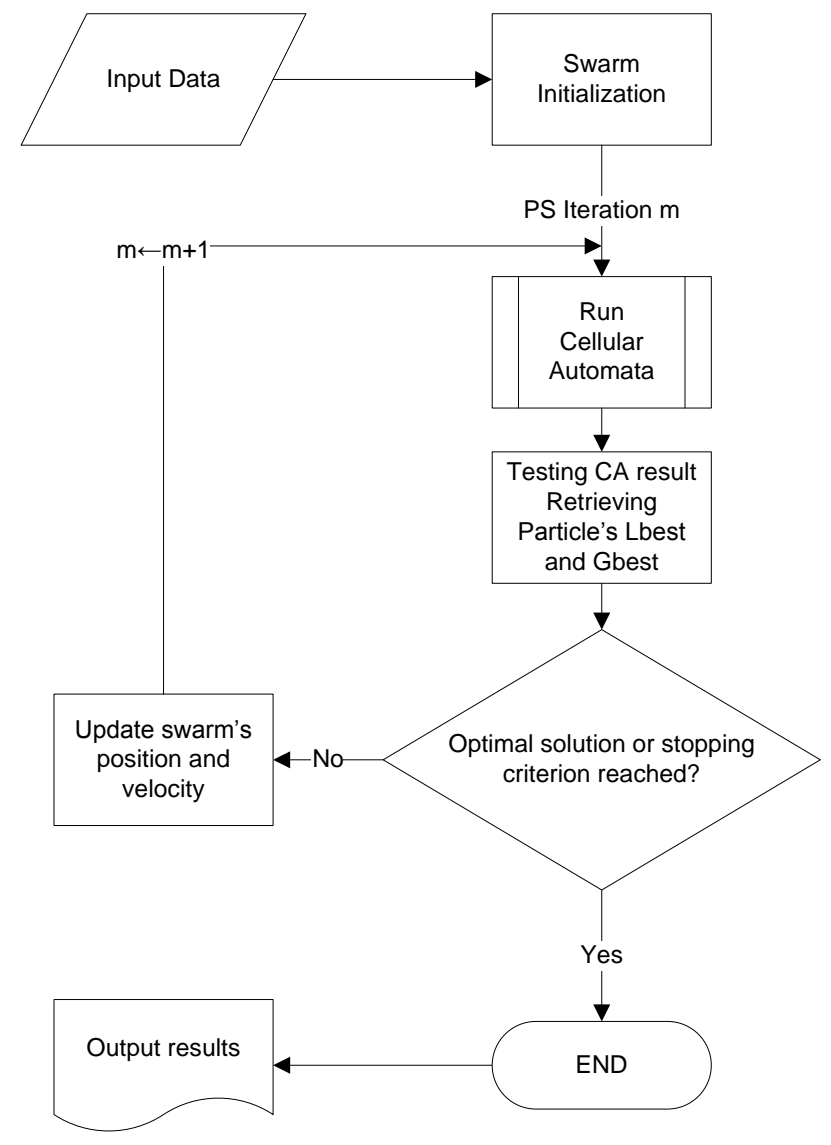

Figure 2 PS algorithm flowchart

The best previous position for the $i^{\text {th }}$ particle is another $D$-dimensional vector $\boldsymbol{P}_{\boldsymbol{i}}$

$$
P_{i}=\left(p_{i 1}, p_{i 2}, \ldots, p_{i D}\right)^{T}
$$

and the global best position of the swarm is represented by the last $D$-dimensional vector $\boldsymbol{P}_{\boldsymbol{g}}$

$$
P_{g}=\left(p_{g 1}, p_{g 2}, \ldots, p_{g D}\right)^{T}
$$

where $g$ is the index for the best particle in the swarm. The velocity vector is updated according to the following expression:

$v_{i, d}^{t+1}=\omega v_{i, d}^{t}+c_{1} r_{1}^{t}\left(p_{i, d}^{t}-x_{i, d}^{t}\right)+c_{2} r_{2}^{t}\left(p_{g, d}^{t}-x_{i, d}^{t}\right)$

where $v_{i, d}{ }^{t}$ is the velocity of particle $i$ on the $d$-dimension at iteration $t, x_{i, d}{ }^{t}$ is the position of particle $i$ on the $d$-dimension at iteration $t, p_{i, d}{ }^{t}$ is the best individual position of particle $i$ on the $d$-dimension at iteration $t, p_{g, d}{ }^{t}$ is the best swarm position of best particle $g$ on the $d$ dimension at iteration $t, \omega$ is the inertia factor, $c_{1}$ is the cognitive parameter, $c_{2}$ is the social 
parameter, $r_{1}{ }^{t}$ and $r_{2}{ }^{t}$ are random numbers uniformly distributed in [0,1]. The position vector is updated according to the following expression:

$$
x_{i, d}^{t+1}=x_{i, d}^{t}+v_{i, d}^{t+1}
$$

\section{Assessing the model and its calibration}

The model was assessed using a set of randomly generated test instances that aim to replicate plausible spatial structures. The use of this type of test instances allows generating a large test sample and is a common method within both theoretical quantitative geography and optimization studies (Batty et al., 1999, Caruso et al., 2007, Santos et al., 2010). Another goal of using hypothetical test instances regards the study of calibration procedures: this method uses spatial structures that can be considered similar to an average small municipality, both in scale and in number of cells. Cells are drawn with Voronoi polygons to represent real world census tracts or blocks, maintaining the irregularity that is a novel characteristic of our CA model. The set of test instances was generated by an algorithm that simulates spatial structures considering a set of conditions for the occupation of each cell. The algorithm initially designs the space with Voronoi polygons as irregular spatial units (with no information associated to them) and using a random maximum dimension of the territory, a random number of cells and a random number of settlements. A hierarchical road network is also designed considering that each cell is served by at least a local access road. Land uses are randomly assigned to cells and population and employment are distributed over the territory. Transition of cell state throughout the years is based on proximity to the main network and on a probability of transition based on a predetermined neighbourhood distance. These instances (of which three examples are depicted in Figure 3) were generated considering a maximum size of the territory (the measure of the side of the square) that ranges from 10 up to $20 \mathrm{~km}$. The number of cells varies between 800 and 1200 . The 
conjugation of these two criteria made possible the generation of different patterns, considering both the dimension and the density of cells.

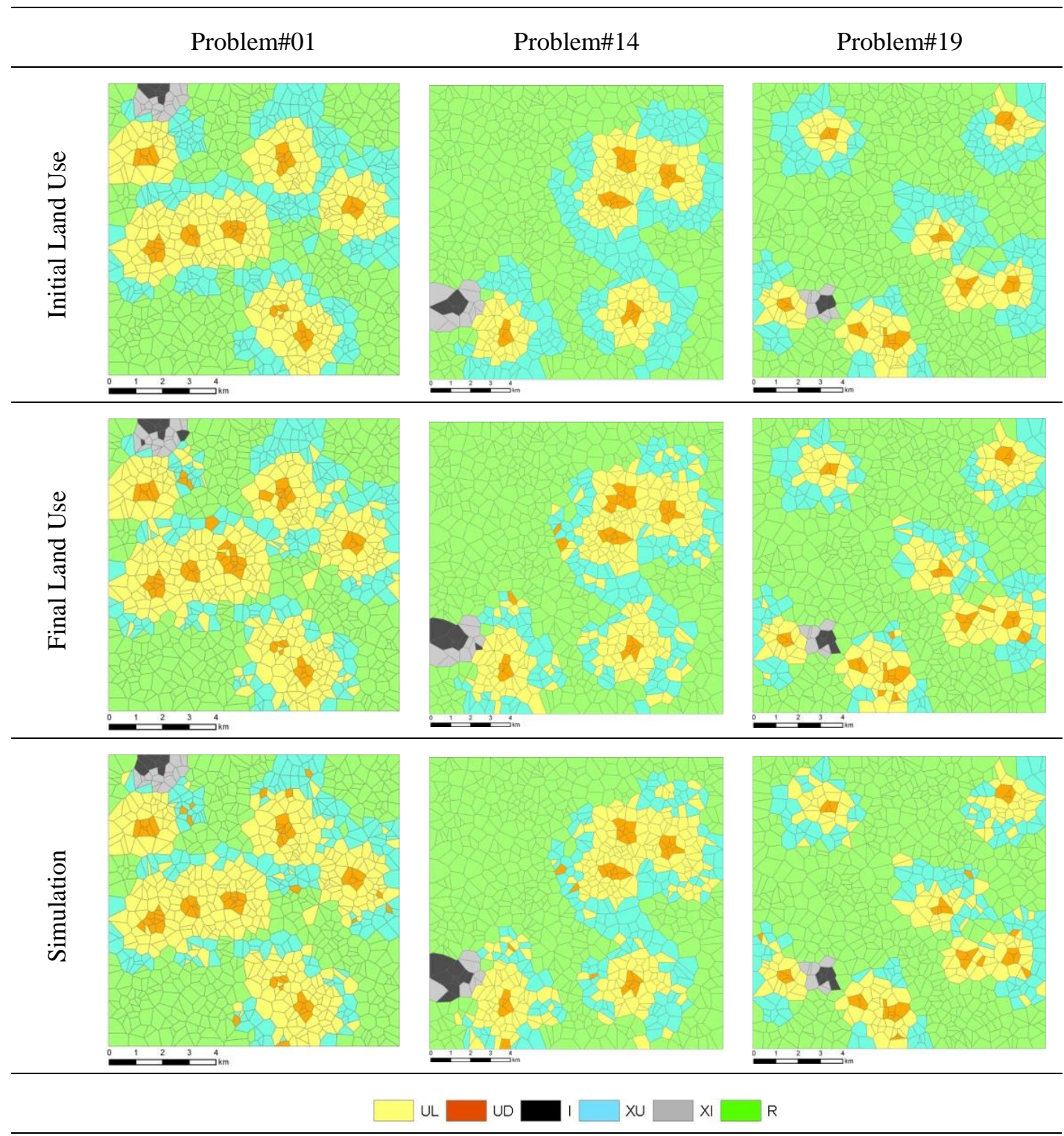

Figure 3 Three examples of hypothetical instances

There are some test instances with high cell density on a small size territory and others also with high cell density on a larger territory. Average cell dimension ranges from 9.6 up to 47 hectares and instance size varies from 114 up to $380 \mathrm{~km}^{2}$. The increase of total UL area varies between $14 \%$ and $46 \%$, while the same value for UH ranges between $7 \%$ and $42 \%$. There is no direct relationship between the variations of these two sums. The change to state UH is made from cells that are both in state $\mathrm{UH}$ and in state XU, while the change for state UL is 
only possible for cells in state XU. This last state presents always a decrease in its total area, as expected. The total increase of built-up urban area (the sum of UL and UH areas) varies from $15 \%$ up to $44 \%$ with an average $27 \%$ increase.

Table 1 presents a series of main indicators for all the 20 test instances.

Table 1 Main characteristics of the set of test instances (UL, UH and XU densities in inhabitants/ha; I densities in employments/ha)

\begin{tabular}{|c|c|c|c|c|c|c|c|c|c|c|c|c|c|c|c|c|c|c|}
\hline \multirow{3}{*}{ Instance\# } & \multirow{3}{*}{ TotalCells } & \multirow{3}{*}{$\begin{array}{c}\text { Max } \\
\text { Dimension } \\
\text { (m) }\end{array}$} & \multirow{3}{*}{$\begin{array}{l}\text { Average Cell } \\
\text { Area (ha) }\end{array}$} & \multirow{3}{*}{$\begin{array}{l}\text { Area } \\
\text { (ha) }\end{array}$} & \multicolumn{4}{|l|}{1991} & \multirow{2}{*}{\multicolumn{4}{|c|}{2001 Population Densities }} & \multirow{2}{*}{\multicolumn{6}{|c|}{ Area variation 1991/2001 }} \\
\hline & & & & & & pulatio & Densiti: & & & & & & & & & & & \\
\hline & & & & & UL & UH & I & $\mathrm{xu}$ & UL & UH & I & $\mathrm{xu}$ & UL & UH & I & $\mathrm{xu}$ & $\mathrm{xI}$ & $\mathbf{R}$ \\
\hline 1 & 933 & 10681 & 12.23 & 11408 & 12.97 & 21.89 & 10.00 & 1.00 & 7.19 & 13.36 & 10.00 & 1.00 & $14 \%$ & $22 \%$ & $34 \%$ & $-20 \%$ & $-10 \%$ & $0 \%$ \\
\hline 2 & 1033 & 15703 & 23.87 & 24658 & 11.69 & 23.80 & 10.00 & 1.00 & 7.23 & 11.95 & 10.00 & 1.00 & $26 \%$ & $20 \%$ & $32 \%$ & $-26 \%$ & $-5 \%$ & $0 \%$ \\
\hline 3 & 1082 & 18214 & 30.66 & 33175 & 13.54 & 29.75 & 10.00 & 1.00 & 6.15 & 11.24 & 10.00 & 1.00 & $27 \%$ & $37 \%$ & $31 \%$ & $-25 \%$ & $-14 \%$ & $0 \%$ \\
\hline 4 & 1132 & 10725 & 10.16 & 11503 & 10.40 & 25.71 & 10.00 & 1.00 & 7.27 & 14.93 & 10.00 & 1.00 & $20 \%$ & $11 \%$ & $12 \%$ & $-40 \%$ & $-3 \%$ & $0 \%$ \\
\hline 5 & 1157 & 16981 & 24.92 & 28835 & 13.83 & 28.68 & 10.00 & 1.00 & 5.63 & 14.58 & 10.00 & 1.00 & $28 \%$ & $7 \%$ & $67 \%$ & $-33 \%$ & $-10 \%$ & $0 \%$ \\
\hline 6 & 1182 & 13236 & 14.82 & 17519 & 12.26 & 21.66 & 10.00 & 1.00 & 6.19 & 14.22 & 10.00 & 1.00 & $20 \%$ & $32 \%$ & $10 \%$ & $-36 \%$ & $-3 \%$ & $0 \%$ \\
\hline 7 & 807 & 19492 & 47.08 & 37994 & 10.69 & 24.64 & 10.00 & 1.00 & 6.75 & 13.87 & 10.00 & 1.00 & $30 \%$ & $29 \%$ & $85 \%$ & $-20 \%$ & $-24 \%$ & $0 \%$ \\
\hline 8 & 832 & 15747 & 29.80 & 24797 & 14.12 & 27.61 & 10.00 & 1.00 & 7.32 & 13.51 & 10.00 & 1.00 & $19 \%$ & $19 \%$ & $37 \%$ & $-24 \%$ & $-9 \%$ & $0 \%$ \\
\hline 9 & 1045 & 13875 & 18.42 & 19252 & 10.83 & 29.10 & 10.00 & 1.00 & 6.50 & 11.14 & 10.00 & 1.00 & $20 \%$ & $25 \%$ & $37 \%$ & $-31 \%$ & $-6 \%$ & $0 \%$ \\
\hline 10 & 85 & 12003 & 16.81 & 14407 & 12.55 & 20.59 & 10.00 & 1.00 & 5.68 & 13.16 & 10.00 & 1.00 & $25 \%$ & $10 \%$ & $16 \%$ & $-22 \%$ & $-5 \%$ & $0 \%$ \\
\hline 11 & 1069 & 10130 & 9.60 & 10262 & 14.26 & 22.08 & 10.00 & 1.00 & 7.06 & 15.18 & 10.00 & 1.00 & $17 \%$ & $36 \%$ & $20 \%$ & $-16 \%$ & $-6 \%$ & $0 \%$ \\
\hline 12 & 882 & 18258 & 37.80 & 33335 & 10.98 & 23.57 & 10.00 & 1.00 & 6.24 & 12.81 & 10.00 & 1.00 & $17 \%$ & $27 \%$ & $35 \%$ & $-12 \%$ & $-14 \%$ & $0 \%$ \\
\hline 13 & 1094 & 16386 & 24.54 & 26850 & 12.69 & 25.05 & 10.00 & 1.00 & 7.62 & 14.83 & 10.00 & 1.00 & $22 \%$ & $42 \%$ & $70 \%$ & $-26 \%$ & $-12 \%$ & $0 \%$ \\
\hline 14 & 907 & 14514 & 23.23 & 21066 & 14.41 & 26.54 & 10.00 & 1.00 & 6.80 & 12.45 & 10.00 & 1.00 & $36 \%$ & $23 \%$ & $70 \%$ & $-26 \%$ & $-23 \%$ & $0 \%$ \\
\hline 15 & 1119 & 12641 & 14.28 & 15979 & 11.12 & 28.03 & 10.00 & 1.00 & 5.98 & 14.47 & 10.00 & 1.00 & $19 \%$ & $36 \%$ & $36 \%$ & $-37 \%$ & $-6 \%$ & $0 \%$ \\
\hline 16 & 932 & 10769 & 12.44 & 11597 & 12.84 & 29.52 & 10.00 & 1.00 & 7.36 & 12.10 & 10.00 & 1.00 & $26 \%$ & $34 \%$ & $24 \%$ & $-28 \%$ & $-8 \%$ & $0 \%$ \\
\hline 17 & 1038 & 14833 & 21.20 & 22002 & 13.69 & 25.26 & 10.00 & 1.00 & 5.85 & 15.31 & 10.00 & 1.00 & $46 \%$ & $24 \%$ & $18 \%$ & $-22 \%$ & $-4 \%$ & $0 \%$ \\
\hline 18 & 1144 & 18897 & 31.21 & 35710 & 14.55 & 21.01 & 10.00 & 1.00 & 6.54 & 14.12 & 10.00 & 1.00 & $35 \%$ & $19 \%$ & $35 \%$ & $-40 \%$ & $-12 \%$ & $0 \%$ \\
\hline 19 & 850 & 12961 & 19.76 & 16799 & 10.41 & 26.75 & 10.00 & 1.00 & 7.23 & 12.93 & 10.00 & 1.00 & $27 \%$ & $17 \%$ & $35 \%$ & $-20 \%$ & $-12 \%$ & $0 \%$ \\
\hline 20 & 950 & 17025 & 30.51 & 28985 & 11.27 & 22.50 & 10.00 & 1.00 & 5.72 & 11.74 & 10.00 & 1.00 & $30 \%$ & $7 \%$ & $52 \%$ & $-25 \%$ & $-11 \%$ & $0 \%$ \\
\hline
\end{tabular}

Each CA model has 38 calibration parameters as explained in the previous section, each one corresponding to one dimension of the space of solutions. Therefore, each particle represents a CA model run which is initialised with a feasible set of parameters.

As for the PS parameters some tests were conducted following the existing literature on the optimal set of parameters (Parsopoulos and Vrahatis, 2002, Trelea, 2003) and the model run with the following set of parameters which consistently gave the best results for the calibration of the CA model $\left(\omega=0.729 ; c_{1}=1.494 ; c_{2}=1.494\right)$. The swarm had 60 particles that run until differences in global best between two iterations were less than 0.1 percent for more than 5 consecutive iterations. 


\section{Discussion of model results}

The analyses produced for evaluating the set of test instances results focus on the performance of the model and on the assessment of model behaviour considering the characteristics of the test instances. Graphic outputs for three instances are depicted in Figure 3. Computational times were therefore high due to the several runs of the CA model with slightly different sets of calibration parameters. Each CA model run took an average 8 seconds but the size of the swarm of particles times the number of PS iterations represented several hours of computing time per test instance. Although these computational times are of the same order as, for example, the ones for early versions of SLEUTH reported by Silva and Clarke (2002) they are not straightforwardly comparable due to the different scales of simulation.

\subsection{Overall accuracy}

Global kMod results for the entire set of instances are depicted in Figure 4. These are the best results achieved by the model and can be considered as good for a simulation process: 50 percent of the instances achieved a kMod around 0.800 or higher and 75 percent of them exceeded 0.750. As it was explained before, kMod is a measure of agreement between modelled and reference maps that do not take into account inactive cell states. Figure 4 also presents the variation of the absolute kappa measure for the set of test instances. Although there is evidence of the limitations of kappa as a reliable measure of agreement (Pontius and Millones, 2011, van Vliet et al., 2011), it is relevant to present this measure to highlight the small difference to our proposed kMod. For 65 percent of the instances, the agreement exceeded 0.900 and 95 percent exceeded 0.850 . Overall accuracy (the proportion of correctly classified cells, that is, the sum of cells located in the main diagonal divided by the total number of cells) for the $k M o d$ measure also exceeded 0.850 for 75 percent of the cases. This 
is to say that the model showed a remarkable capacity to capture land use dynamics when dealing with hypothetical small urban areas.

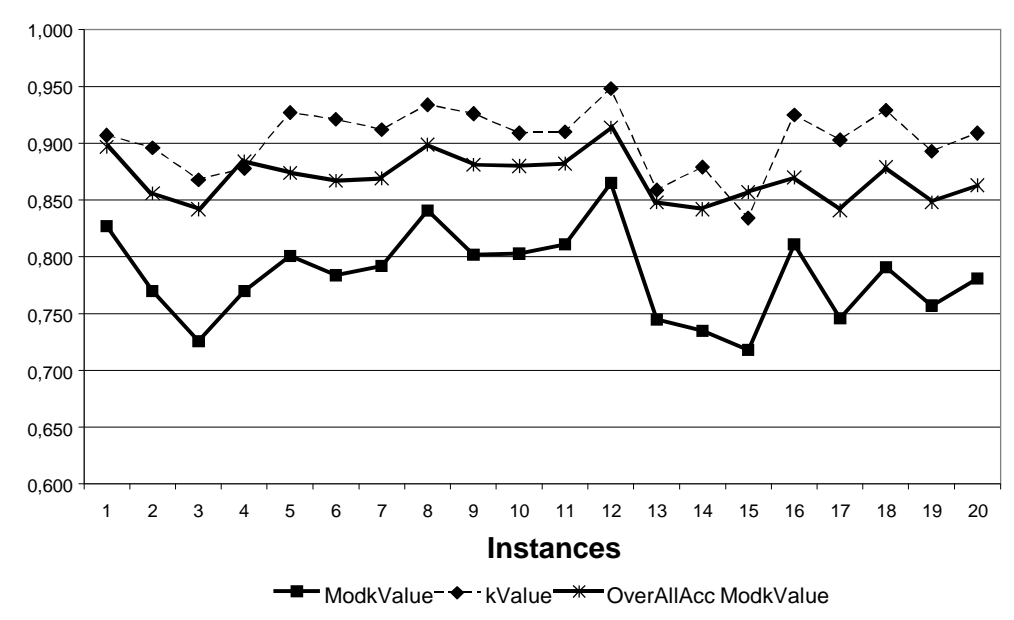

Figure 4 Global $k M o d$ and kappa results for the set of test instances

Another measure used to assess the performance of the simulation is the number of cells that have changed for the same state both in simulation and in reference maps. This value can be referred to as a proportion of the total number of cells that have correctly changed state in simulation. For 80 percent of the instances a matching proportion higher than 35 percent was achieved, with 20 percent of the entire set achieving more than 50 percent. Although these proportions present low values, they can be considered a good indicator of the model's capacity to simulate urban change phenomena. The model was unable to match a large number of state changes. However, it was quite able to choose cells that were close to the ones whose change was not matched. These contiguous cells have similar values for transition potential because of similar values in one or more of the components of the transition potential (accessibility, suitability or neighbourhood effects).

\subsection{Accuracy by cell state}

Another measurement of good agreement can be assessed from the conditional kMod, the chance of agreement for each cell state within the contingency matrix. The conditional kMod 
for urban cell states (UL, UH, and XU) is depicted in Figure 5 (a). It is notorious for a variability of the values not only across the instance set but also within cell states.

Good results were obtained for UH cell state, with 80 percent of the instances with more than 0.800 for the conditional kMod. For the other cell states lower values were obtained, particularly cell state XU, for which only 35 percent of the instances achieved values of conditional $k M o d$ higher than 0.800 . It is interesting to note that 40 percent of the instances have differences for UL and UH conditional $k M o d$ smaller than 0.050 which indicates a good matching of the cells that changed state.

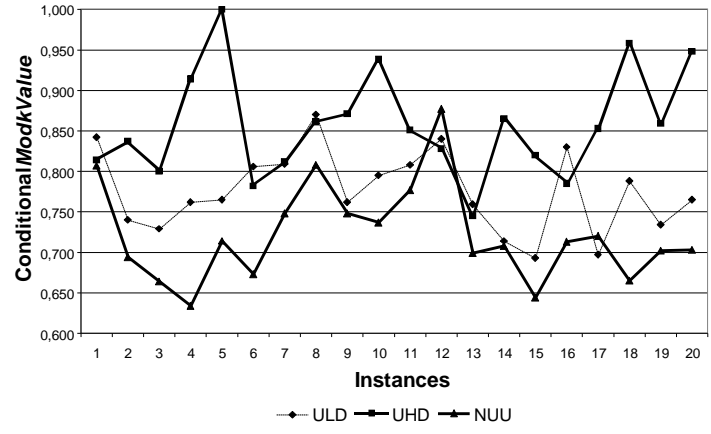

(a)

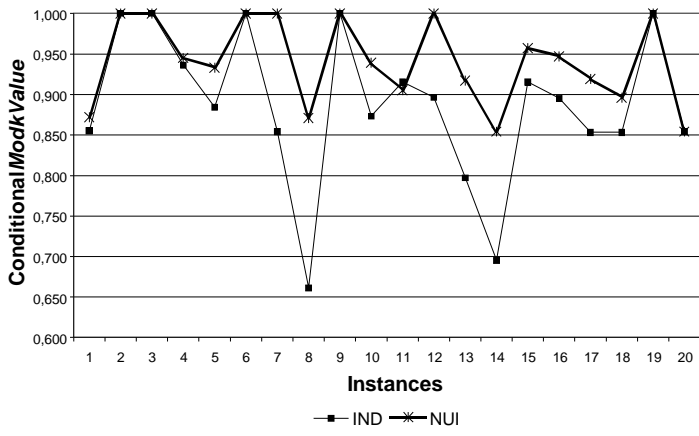

(b)

Figure 5 Global conditional $k M o d$ results for the set of test problem

For industrial land uses the results obtained show higher values of agreement (Figure 5 (b)). The simplicity of the instances with regard to industrial land uses contributes to these good results. For 85 percent of the instances conditional $k M o d$ for the I cell state exceeded 0.850 and the entire the set also exceeded this value for XI conditional $k M o d$. And 25 percent of the entire set achieved total agreement for the two industrial land uses, with both values of conditional kMod equalizing 1, which means that there was total agreement between simulation and reality for both these land uses.

Another important parameter for model evaluation is the relationship between modelled and reference areas for each active cell state. They were compared by ratio $\Theta_{S}$ that is calculated through Equation 11 and aims to assess how different the final model outcome is from the 
reference map in terms of total area occupied by each land use. It is important to assess this ratio because land use demand is considered as a function of the population and the model aims to capture the distribution of population throughout the territory.

$\Theta_{S}=\frac{\left(\sum_{i \in C, s=S} \Omega_{i}{ }^{M o d}-\sum_{i \in C, s=S} \Omega_{i}{ }^{\operatorname{Re} f}\right)}{\sum_{i \in C, s=S} \Omega_{i}^{\operatorname{Re} f}} \times 100$

where $\Theta_{S}$ is the ratio between areas for state $\mathrm{S}, \Omega_{i}^{\text {Mod }}$ is the sum of the areas of every cell $\mathrm{i}$ in state $\mathrm{s}=\mathrm{S}$ in the simulation, and $\Omega_{i}^{R e f}$ is the sum of the areas of every cell $i$ in state $s=S$ in the reference map. The total area was determined for each cell state both for modelled and reference maps. The values for the ratio $\Theta_{S}$ are depicted in Figure 6 for every active land use for the set of test instances.

The variation of total area for UL cell state takes values between $0 \%$ and $+4 \%$ with an average of $+1 \%$; for $\mathrm{UH}$ cell state this variation takes values between $-13 \%$ and $0 \%$, with an average of $-5 \%$; for $\mathrm{XU}$ cell state this variation takes values between $-4 \%$ and $+1 \%$ with an average of $-1 \%$. These values show that the model is capable of evolving to a situation similar to reality in terms of total occupied area. Differences between modelled and reference maps derive from the existence of similar values of transition potential for neighbouring cells as a consequence of similar accessibility conditions and neighbourhoods. The model chooses cells near or even directly connected to cells that have changed in the reference map but not in the simulation.

The variation of total area for industrial land uses is significantly higher than the values obtained for urban land uses. The values for I cell state vary from $0 \%$ up to $+49 \%$ with an average of $+12 \%$. For XI cell state the variation of total area takes values between $-20 \%$ and $0 \%$ with an average of $-5 \%$. This behaviour for industrial land uses may be explained by the excessive simplicity of test instances because there are few options for change in these land 
uses. Therefore, a small difference between modelled and reference maps (one or two cells) may result in a large difference in the corresponding area ratios.

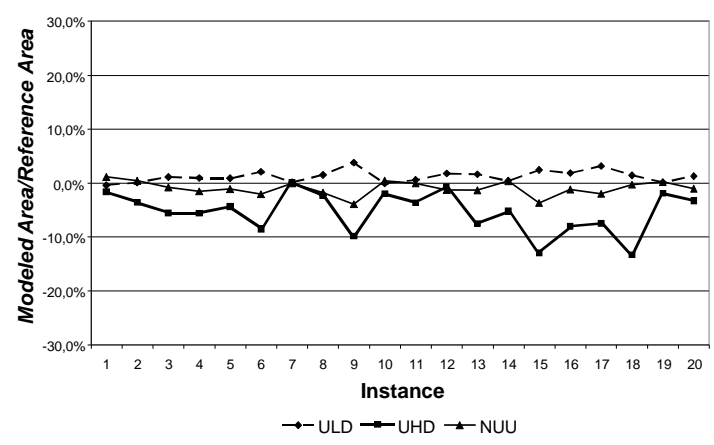

(a)

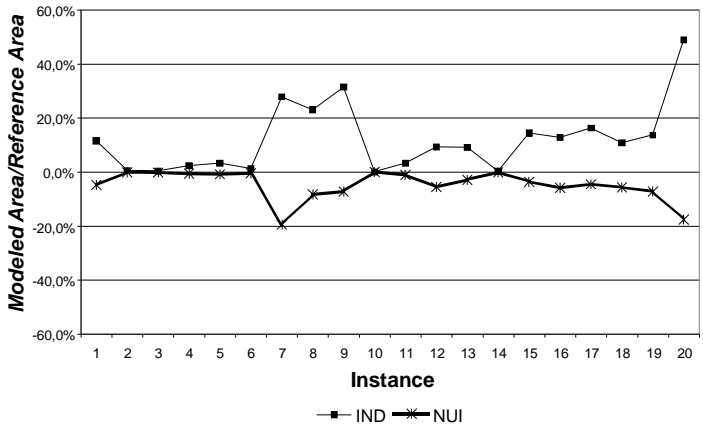

(b)

Figure 6 Ratio between modelled and reference area by cell state, $\Theta_{S}$

\subsection{CA parameters}

Neighbourhood distance $\delta$ varies between 2.1 and $8.0 \mathrm{~km}$ with an average $3.9 \mathrm{~km}$. The accessibility calibration parameters show some variability in their results. For 45 percent of the instances $\alpha_{A}$ (calibration parameter for the distance to the municipality main town) was the maximum value among all the accessibility parameters. The other parameters, the calibration parameters for the distance to the civil parish $\beta_{A}$ and to the industrial area $\gamma_{A}$ took the maximum value among them all for 35 percent and 20 percent each, respectively. This indicates a possible trend that may evidence the importance that the distance to the main functional centre (the municipality main town) has for the formation of the accessibility measure. Regarding the calibration parameters for the transition potential $-\chi_{P}$ for accessibility, $v_{P}$ for suitability, and $\theta_{P}$ for neighbourhood effect - the existence of a trend seems to be more evident. Both $v_{P}$ and $\theta_{P}$, the calibration parameters for suitabilities and for neighbourhood effect respectively, took the maximum value among the transition potential parameters for only 15 percent and 35 percent of the instances, respectively. The majority of 
the instances - 55 percent - took its maximum value for the accessibility calibration parameter, $\chi_{P}$. This distribution suggests the existence of a trend that gives importance to accessibility in the account of the transition potential. However, it is believed that more sophisticated measures would improve significantly the distinction between the influence that different transition potential components have in the final outcome, thus improving the quality of the simulation.

\subsection{Ability to simulate urban change in small urban areas}

Finally, it is important to evaluate the relationship between performance and instance size in order to assess the model's ability to simulate urban change for this typology of small urban areas. Two measures were considered: the total number of cells and the proportion of cells in active states over the total number of cells. The relationship between the measure of performance of the model $k M o d$ and the number of cells is depicted in Figure 7 . There is a small correlation factor $R^{2}$ of 0.138 . This value indicates the existence of a tenuous linear relationship between these two variables: larger values of the number of cells are related to worst values of performance. This correlation has statistical significance with a $F$-test score of 0.014 for a $95 \%$ confidence interval. Although the level of correlation is very low, this behaviour might be a consequence of a higher number of cells that can change when the number of cells increases. The relationship between the performance measure and the proportion of cells in active states from the total number of cells is depicted in Figure 8. The proportion of active cells is considered a good parameter for assessing problem size because it only considers the number of cells that participate in land use dynamics. This relationship presents a $R^{2}$ factor of 0.221 indicating a higher, though still small, linear correlation between the two variables. This correlation also has statistical significance with a F-test score of 0.0005 for a $95 \%$ confidence interval. This correlation is in line with the one depicted in 
Figure 7 as the higher number of cells with active cell states that can change leads to more possible combinations of change, thus reducing the final accuracy.

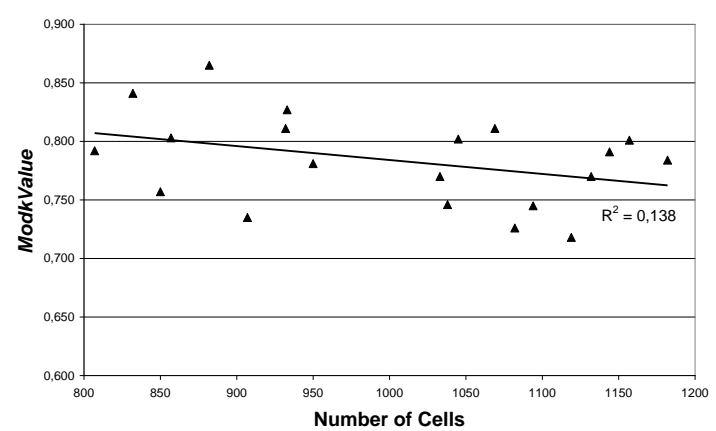

Figure 7 Relationship between $k M o d$ and number of cells

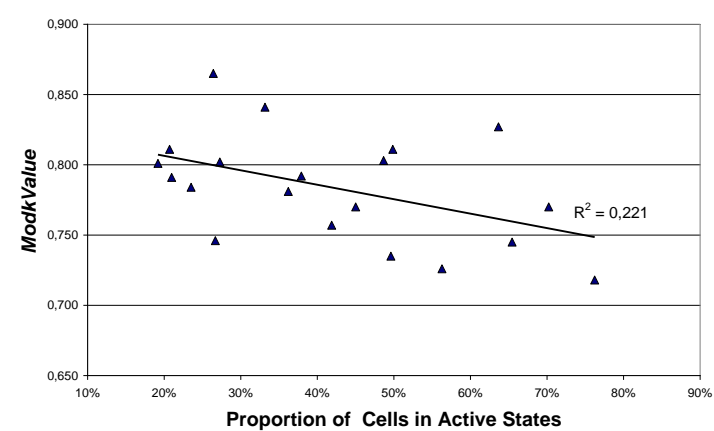

Figure 8 Relationship between $k M o d$ and the proportion of cells in active states

\section{Conclusions}

The results show promising possibilities of using CA for modelling urban change in small urban areas, in line with what is presented in other implementations of the model (Pinto and Antunes, 2010). The use of irregular cells also proved to be feasible as model results compare very well with existing results in the literature for the same performance (Petrov et al., 2009, Grinblat et al., 2016, Barredo et al., 2003, Barredo and Demicheli, 2003, Engelen et al., 2002). Irregular cells combine a more representative urban form with more sophisticated datasets like census or employment data, whereas the traditional regular cells are more arbitrary partitions of space and usually only held information about land use. The use of irregular CA models has, however, some limitations, namely if applied to geographical contexts where the basic data infrastructure (e.g. the census spatial structure) is not fully developed, for which the use of raster images with regular cells is more practical to simulate land use dynamics. The model is based on the assessment of a transition potential that is a function of several components, such as accessibility, land suitability, and neighbourhood relationships. Although the results for simulation agreement are closer to commonly accepted 
thresholds for other spatial analysis (such as remote sensing), the model showed signs that there is a significant margin to improve the assessment of the three components of the transition potential. The concept of neighbourhood should be more oriented for real urban structures rather than to its mathematical concept. The assessment of neighbourhood relationships is another field that needs careful research. The use of a local scale CA model is believed to produce good simulation results for urban change phenomena, as our results are comparable with the results reported in the literature for larger urban areas. The integration of CA with other models specifically designed for simulating accessibility, physical suitabilities and land use demand is believed to lead to the development of useful modelling tools ultimately aimed to assist planning processes.

Particle swarm proved to be a feasible approach to CA calibration as it dealt well with the large number of calibration parameters. Despite the large computational time spent (each CA model run as many times as the number of particles times the number of iterations), which was expected due to the architecture of the model, the results are encouraging as the CA model was very able to simulate the reference reality and to achieve very high performance scores, using the kMod measure and compared with the literature where traditional kappa measurements are considered. Further research on coupling PS and CA must focus on the consideration of particle acceleration and sub-swarms to improve local search.

\section{Acknowledgements}

Nuno Pinto wishes to acknowledge the valuable support received from Fundação para a Ciência e a Tecnologia under grant SFRH/BD/37465/2007 to do this research.

\section{References}

ABOLHASANI, S., TALEAI, M., KARIMI, M. \& REZAEE NODE, A. 2016. Simulating urban growth under planning policies through parcel-based cellular automata (ParCA) model. International Journal of Geographical Information Science, 30, 2276-2301. 
ALMEIDA, C. M., GLERIANI, J. M., CASTEJON, E. F. \& SOARES, B. S. 2008. Using neural networks and cellular automata for modelling intra-urban land-use dynamics. International Journal of Geographical Information Science, 22, 943-963.

ALTARTOURI, A., NURMINEN, L. \& JOLMA, A. 2015. Spatial neighborhood effect and scale issues in the calibration and validation of a dynamic model of Phragmites australis distribution - A cellular automata and machine learning approach. Environmental Modelling \& Software, 71, 15-29.

BARREDO, J. I. \& DEMICHELI, L. 2003. Urban sustainability in developing countries' megacities: modelling and predicting future urban growth in Lagos. Cities, 20, 297-310.

BARREDO, J. I., KASANKO, M., MCCORMICK, N. \& LAVALLE, C. 2003. Modelling dynamic spatial processes: simulation of urban future scenarios through cellular automata. Landscape and Urban Planning, 64, 145-160.

BARREIRA-GONZÁLEZ, P., GÓMEZ-DELGADO, M. \& AGUILERA-BENAVENTE, F. 2015. From raster to vector cellular automata models: A new approach to simulate urban growth with the help of graph theory. Computers, Environment and Urban Systems, 54, 119131.

BASSE, R. M., OMRANI, H., CHARIF, O., GERBER, P. \& BÓDIS, K. 2014. Land use changes modelling using advanced methods: Cellular automata and artificial neural networks. The spatial and explicit representation of land cover dynamics at the cross-border region scale. Applied Geography, 53, 160-171.

BATTY, M. 2005. Cities and complexity : understanding cities with cellular automata, agent-based models, and fractals, Cambridge, MA, London, MIT Press.

BATTY, M. \& XIE, Y. 1994. From Cells to Cities. Environment and Planning B-Planning \& Design, 21, S31-S38. 
BATTY, M. \& XIE, Y. 1997. Possible urban automata. Environment and Planning BPlanning \& Design, 24, 175-192.

BATTY, M., XIE, Y. \& SUN, Z. 1999. Modeling urban dynamics through GIS-based cellular automata. Computers, Environment and Urban Systems, 23, 205-233.

BONYADI, M. R. \& MICHALEWICZ, Z. 2016. Particle Swarm Optimization for Single Objective Continuous Space Problems: A Review. Evolutionary Computation, 25, 1-54.

CAO, K., HUANG, B., LI, M. \& LI, W. 2013. Calibrating a cellular automata model for understanding rural-urban land conversion: a Pareto front-based multi-objective optimization approach. International Journal of Geographical Information Science, 28, 1028-1046.

CAO, M., TANG, G. A., SHEN, Q. \& WANG, Y. 2015. A new discovery of transition rules for cellular automata by using cuckoo search algorithm. International Journal of Geographical Information Science, 29, 806-824.

CARUSO, G., PEETERS, D., CAVAILHES, J. \& ROUNSEVELL, M. 2007. Spatial configurations in a periurban city. A cellular automata-based microeconomic model. Regional Science and Urban Economics, 37, 542-567.

CHEN, Y., LI, X., LIU, X. \& AI, B. 2014. Modeling urban land-use dynamics in a fast developing city using the modified logistic cellular automaton with a patch-based simulation strategy. International Journal of Geographical Information Science, 28, 234-255.

CLARKE, K., HOPPEN, S. \& GAYDOS, L. 1997. A self-modifying cellular automaton model of historical urbanization in the San Francisco Bay area. Environment and Planning B: Planning and Design, 24, 247-261.

CONGALTON, R. \& GREEN, K. 2009. Assessing the accuracy of remotely sensed data. COUCLELIS, H. 1985. Cellular worlds - a framework for modeling micro-macro dynamics. Environment and Planning A, 17, 585-596. 
COUCLELIS, H. 1997. From cellular automata to urban models: new principles for model development and implementation. Environment and Planning B: Planning and Design, 24, $165-174$.

COUCLELIS, H. 2005. "Where has the future gone?" Rethinking the role of integrated landuse models in spatial planning. Environment and Planning A, 37, 1353-1371.

COUTO, P. 2003. Assessing the accuracy of spatial simulation models. Ecological Modelling, 167, 181-198.

ENGELEN, G., WHITE, R., ULJEE, I. \& DRAZAN, P. 2002. The MURBANDY and MOLAND models for Dublin. Ispra: European Commission Joint Research Centre.

FENG, Y. \& LIU, Y. 2012. A heuristic cellular automata approach for modelling urban landuse change based on simulated annealing. International Journal of Geographical Information Science, 27, 449-466.

FENG, Y., LIU, Y., TONG, X., LIU, M. \& DENG, S. 2011. Modeling dynamic urban growth using cellular automata and particle swarm optimization rules. Landscape and Urban Planning, 102, 188-196.

GRINBLAT, Y., GILICHINSKY, M. \& BENENSON, I. 2016. Cellular Automata Modeling of Land-Use/Land-Cover Dynamics: Questioning the Reliability of Data Sources and Classification Methods. Annals of the American Association of Geographers, 106, 12991320.

GUAN, Q. F. \& CLARKE, K. C. 2010. A general-purpose parallel raster processing programming library test application using a geographic cellular automata model. International Journal of Geographical Information Science, 24, 695-722.

HASSAN, R., COHANIM, B., DE WECK, O. \& VENTER, G. 2005. A Comparison of Particle Swarm Optimization and the Genetic Algorithm. 46th AIAA/ASME/ASCE/AHS/ASC 
Structures, Structural Dynamics and Materials Conference. American Institute of Aeronautics and Astronautics.

JAFARNEZHAD, J., SALMANMAHINY, A. \& SAKIEH, Y. 2016. Subjectivity versus Objectivity: Comparative Study between Brute Force Method and Genetic Algorithm for Calibrating the SLEUTH Urban Growth Model. Journal of Urban Planning and Development, 142, 05015015.

KENNEDY, J. 1997. The particle swarm: Social adaptation of knowledge. 1997 IEEE International Conference on Evolutionary Computation (ICEC '97). INDIANAPOLIS, IN.

KENNEDY, J. \& EBERHART, R. 1995. Particle swarm optimization. Ieee International Conference on Neural Networks Proceedings, Vols 1-6, 1942-1948.

LEE, D. B. 1973. Requiem for Large-Scale Models. Journal of the American Institute of Planners, 39, 163-178.

LI, X., LAO, C., LIU, Y., LIU, X., CHEN, Y., LI, S., AI, B. \& HE, Z. 2013. Early warning of illegal development for protected areas by integrating cellular automata with neural networks. Journal of Environmental Management, 130, 106-116.

LI, X., LIU, X. \& YU, L. 2014. A systematic sensitivity analysis of constrained cellular automata model for urban growth simulation based on different transition rules. International Journal of Geographical Information Science, 28, 1317-1335.

LI, X. \& YEH, A. G.-O. 2002. Neural-network-based cellular automata for simulating multiple land use changes using GIS. International Journal of Geographical Information Science, 16, 323 - 343.

LIAO, J., TANG, L., SHAO, G., QIU, Q., WANG, C., ZHENG, S. \& SU, X. 2014. A neighbor decay cellular automata approach for simulating urban expansion based on particle swarm intelligence. International Journal of Geographical Information Science, 28, 720-738. 
LIN, J., HUANG, B., CHEN, M. \& HUANG, Z. 2014. Modeling urban vertical growth using cellular automata—Guangzhou as a case study. Applied Geography, 53, 172-186.

MORENO, N., MÉNARD, A. \& MARCEAU, D. J. 2008. VecGCA: a vector-based geographic cellular automata model allowing geometric transformations of objects. Environment and Planning B: Planning and Design, 35, 647-665.

MORENO, N., WANG, F. \& MARCEAU, D. 2009a. Computers, Environment and Urban Systems, 33, 44.

MORENO, N., WANG, F. \& MARCEAU, D. J. 2009b. Implementation of a dynamic neighborhood in a land-use vector-based cellular automata model. Computers, Environment and Urban Systems, 33, 44-54.

O' SULLIVAN, D. 2001a. Exploring spatial process dynamics using irregular cellular automaton models. Geographical Analysis, 33, 1-18.

O' SULLIVAN, D. 2001b. Graph-based cellular automaton models of urban spatial processes. $\mathrm{PhD}$, Bartlett School of Architecture and Planning, University College London. ONSTED, J. A. \& CHOWDHURY, R. R. 2014. Does zoning matter? A comparative analysis of landscape change in Redland, Florida using cellular automata. Landscape and Urban Planning, 121, 1-18.

PARSOPOULOS, K. E. \& VRAHATIS, M. N. 2002. Recent approaches to global optimization problems through Particle Swarm Optimization. Natural Computing, 1, 235306.

PETROV, L. O., LAVALLE, C. \& KASANKO, M. 2009. Urban land use scenarios for a tourist region in Europe: Applying the MOLAND model to Algarve, Portugal. Landscape and Urban Planning, 92, 10-23. 
PINTO, N. N. \& ANTUNES, A. P. 2010. A cellular automata model based on irregular cells: application to small urban areas. Environment and Planning B-Planning \& Design, 37, 10951114.

PONTIUS, R. G. \& MILLONES, M. 2011. Death to Kappa: birth of quantity disagreement and allocation disagreement for accuracy assessment. International Journal of Remote Sensing, 32, 4407-4429.

RIENOW, A. \& GOETZKE, R. 2015. Supporting SLEUTH - Enhancing a cellular automaton with support vector machines for urban growth modeling. Computers, Environment and Urban Systems, 49, 66-81.

SAKIEH, Y., SALMANMAHINY, A., JAFARNEZHAD, J., MEHRI, A., KAMYAB, H. \& GALDAVI, S. 2015. Evaluating the strategy of decentralized urban land-use planning in a developing region. Land Use Policy, 48, 534-551.

SANTOS, B. F., ANTUNES, A. P. \& MILLER, E. J. 2010. Interurban road network planning model with accessibility and robustness objectives. Transportation Planning and Technology, $33,297-313$.

SEMBOLONI, F. 1997. An urban and regional model based on cellular automata. Environment and Planning B: Planning and Design, 24, 589-612.

SEMBOLONI, F. 2000. The growth of an urban cluster into a dynamic self-modifying spatial pattern. Environment and Planning B: Planning and Design, 27, 549-564.

SILVA, E. \& CLARKE, K. C. 2002. Calibration of the SLEUTH urban growth model for Lisbon and Porto, Portugal. Computers, Environment and Urban Systems, 26, 525-552.

STEVENS, D. \& DRAGICEVIC, S. 2007. A GIS-based irregular cellular automata model of land-use change. Environment and Planning B: Planning and Design, 34, 708-724.

STEVENS, D., DRAGICEVIC, S. \& ROTHLEY, K. 2007. iCity: A GIS-CA modelling tool for urban planning and decision making. Environmental Modelling \& Software, 22, 761-773. 
TOBLER, W. 1979. Cellular geography. In: GALE, S. \& OLSSON, G. (eds.) Philosophy in Geography. Boston: D. Reidel.

TRELEA, I. C. 2003. The particle swarm optimization algorithm: convergence analysis and parameter selection. Information Processing Letters, 85, 317-325.

VAN DEN BERGH, F. \& ENGELBRECHT, A. P. 2006. A study of particle swarm optimization particle trajectories. Information Sciences, 176, 937-971.

VAN VLIET, J., BREGT, A. K. \& HAGEN-ZANKER, A. 2011. Revisiting Kappa to account for change in the accuracy assessment of land-use change models. Ecological Modelling, 222, 1367-1375.

VLIET, J. V., WHITE, R. \& DRAGICEVIC, S. 2009. Modeling urban growth using a variable grid cellular automaton. Computers, Environment and Urban Systems, 33, 35-43.

WANG, F. \& MARCEAU, D. J. 2013. A Patch-based Cellular Automaton for Simulating Land-use Changes at Fine Spatial Resolution. Transactions in GIS, 17, 828-846.

WARD, D., MURRAY, A. \& PHINN, S. 2000. A stochastically constrained cellular model of urban growth. Computers, Environment and Urban Systems, 24, 539-558.

WARD, D., MURRAY, A. \& PHINN, S. 2003. Integrating spatial optimization and cellular automata for evaluating urban change. Annals of Regional Science, 37, 131-148.

WHITE, R. \& ENGELEN, G. 1993. Cellular automata and fractal urban form: a cellular modelling approach to the evolution of urban land-use patterns. Environment and Planning A, 25, 1175-1199.

WHITE, R. \& ENGELEN, G. 1997. Cellular automata as the basis of integrated dynamic regional modelling. Environment and Planning B: Planning and Design, 24, 235-246.

WHITE, R., ENGELEN, G. \& ULJEE, I. 1997. The use of constrained cellular automata for high-resolution modelling of urban land-use dynamics. Environment and Planning BPlanning \& Design, 24, 323-343. 
WU, F. 1998. SimLand: a prototype to simulate land conversion through the integrated GIS and CA with AHP-derived transition rules. International Journal of Geographical Information Science, 12, 63 - 82. 